\title{
Milliscale self-integration of megamolecule biopolymers on a drying gas-aqueous liquid crystalline interface
}

\author{
Kosuke Okeyoshi*, Maiko K. Okajima, Tatsuo Kaneko* \\ Japan Advanced Institute of Science and Technology \\ 1-1 Asahidai, Nomi, Ishikawa 923-1292, Japan \\ *Correspondence and requests for materials should be addressed to \\ K. O. (Email: okeyoshi@jaist.ac.jp) \\ T.K. (Email: kaneko@jaist.ac.jp)
}




\section{Supplementary Movie S1.}

Drying process of sacran solution and pure water during drying at $60^{\circ} \mathrm{C}$. Scale bar: $5 \mathrm{~mm}$. see Fig. $2 A$ and Fig. S3.

\section{Supplementary Movie S2.}

Drying process of xanthan gum solution during drying at $25^{\circ} \mathrm{C}, 40^{\circ} \mathrm{C}$, and $60^{\circ} \mathrm{C}$. Scale bar: $5 \mathrm{~mm}$. see Fig. 4A.

\section{Supplementary Movie S3.}

Drying process of sacran, MTs, and DNA solutions at $37^{\circ} \mathrm{C}$. Scale bar: $5 \mathrm{~mm}$. see Fig. 5A. 


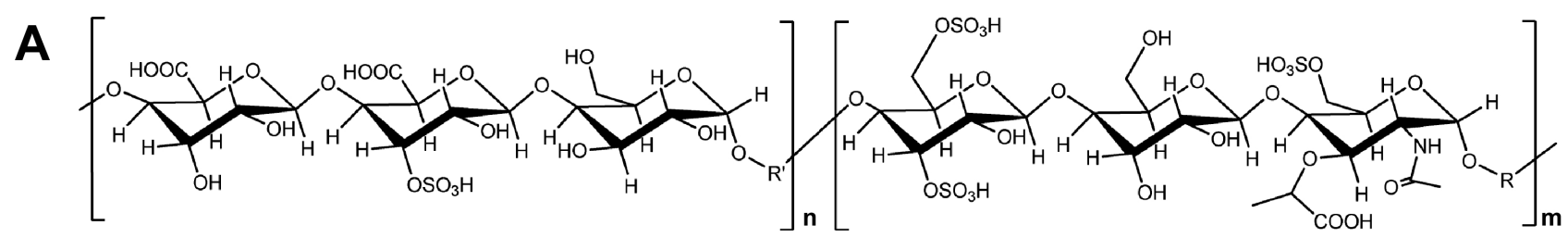

B

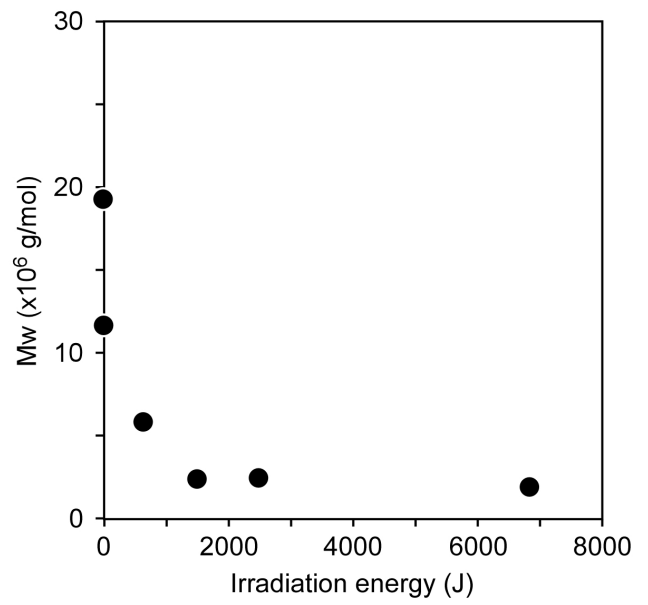

Figure S1. A. Chemical structure of sacran. B. Effect of irradiation energy during ultrasonication on molecular weight. Irradiation energy was calculated from irradiation time. The average molecular weight, $M_{\mathrm{w}}$, was determined using the Berry model with the SEC-MALLS system.

Elemental analyses and chromatographic and spectroscopic studies of sacran revealed the following sugar residues: Glc, Gal, Man, Fuc, Rha, Xyl, Rib, methylated hexose, uronic acids, and trace muramic acid. The carboxylate composition of sacran was $11 \mathrm{~mol} \%$, and substitution of sulphate groups was favoured when the sulphate composition was 22 mol\% with sugar residues. ${ }^{[1-5]}$ 

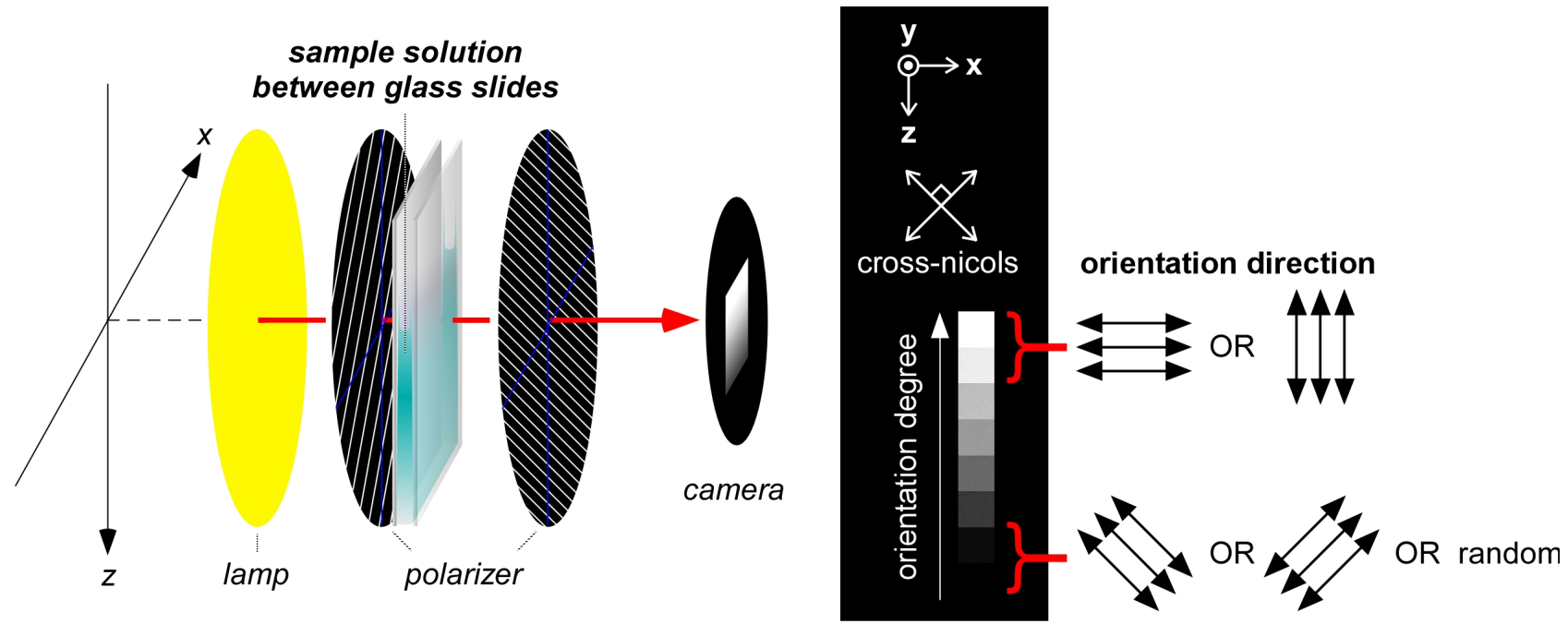

Figure S2. Schematic illustration of the experimental setup used for observations under cross-polarized light. The polarizers were normally adjusted to $45^{\circ}$ and $135^{\circ}$.

A

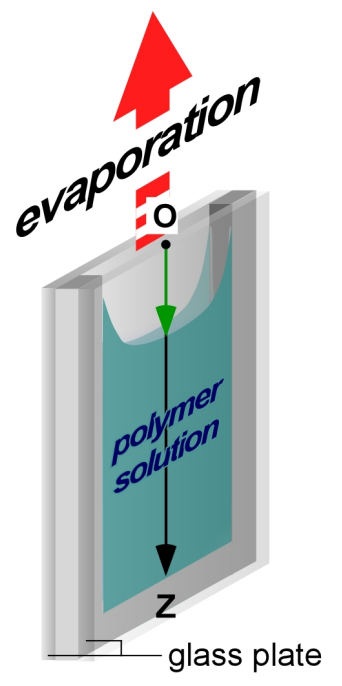

B

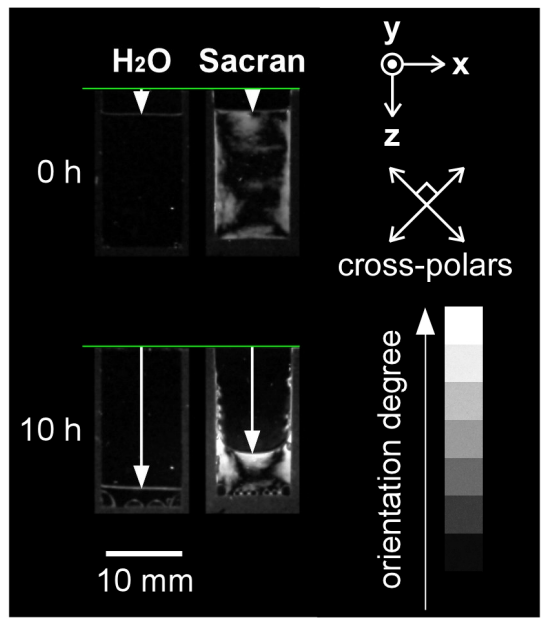

C

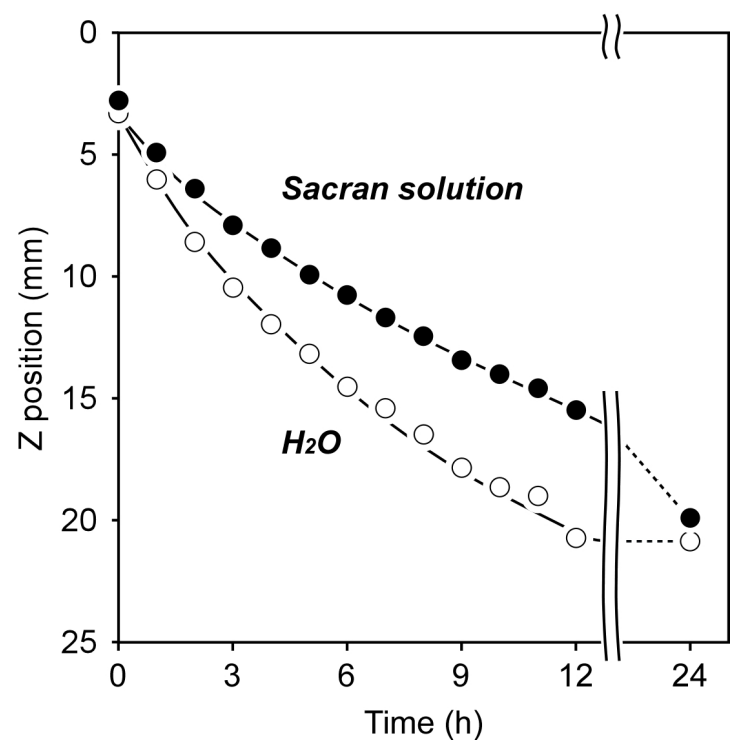

Figure S3. Comparison of gas-liquid interfacial Z-position between polymer solution and water during the drying process from a one-side open cell $(10 \mathrm{~mm} \times 1 \mathrm{~mm} \times \sim 20 \mathrm{~mm})$.

The drying process for the polymer solution and pure water were compared. The descent of the gas-liquid interface of the polymer solution was slower than that of pure water. The oriented domains on the gas-liquid interface caused the slower evaporation rate, working like a skin layer. The evaporated volume of the polymer solution was approximately two-thirds of that of pure water. 


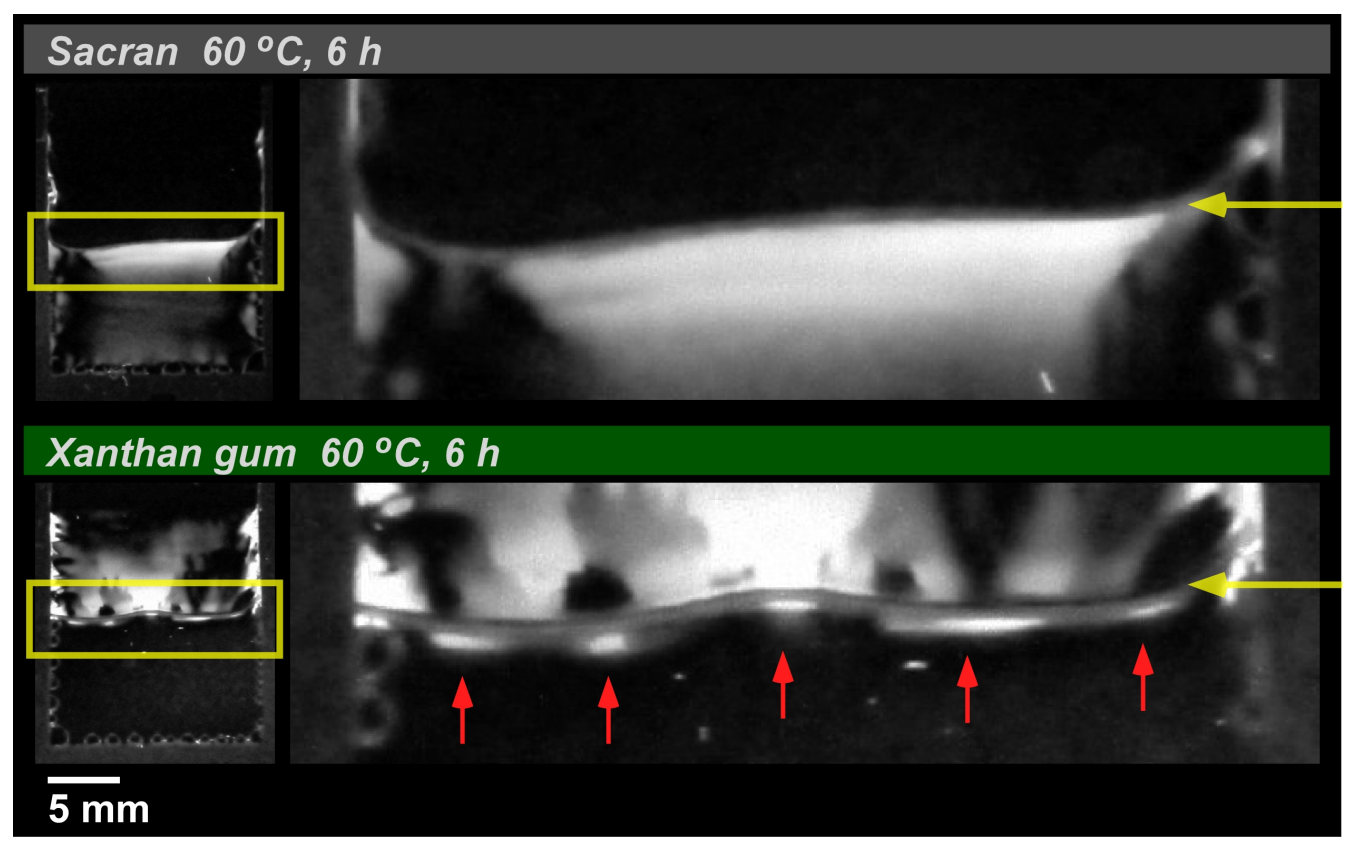

gas-liquid interface

gas-liquid interface

Figure S4. Side views of sacran and xanthan gum solutions after 6 hours drying at $60^{\circ} \mathrm{C}$ under cross-polarized light.
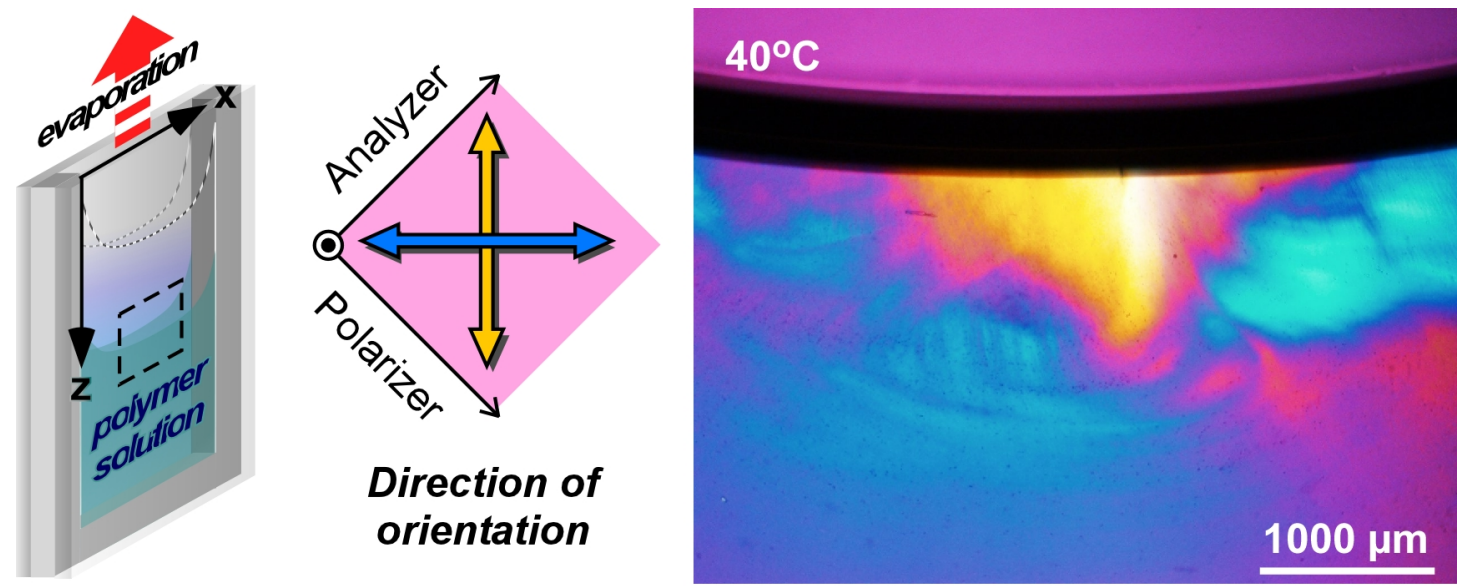

Direction of orientation

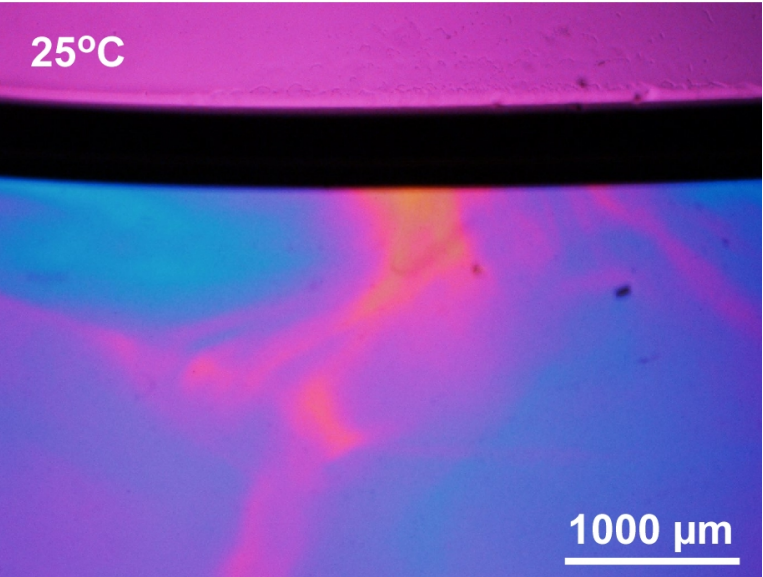

Figure S5 Microscopic images of the xanthan gum solutions in the glass cell observed through the cross-nicols with a first order retardation plate $(\lambda=530 \mathrm{~nm})$ after 6 hours drying at $60^{\circ} \mathrm{C}$. Initial concentration: $0.5 \mathrm{wt} \%$. 

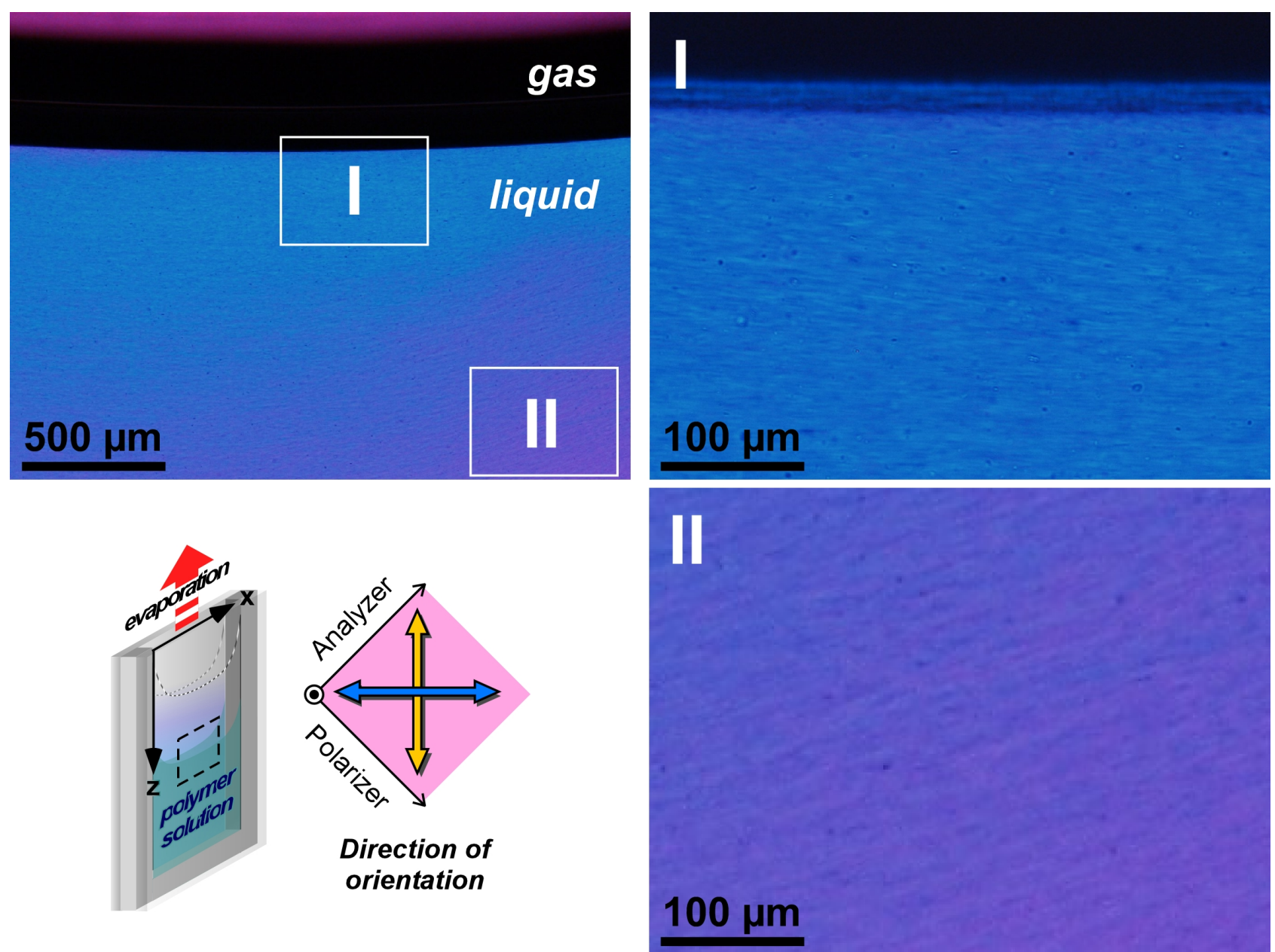

Figure S6. Microscopic images of the sacran solutions in the glass cell observed through the cross-nicols with a first order retardation plate $(\lambda=530 \mathrm{~nm})$ after 6 hours drying at $60^{\circ} \mathrm{C}$. Initial concentration: $0.5 \mathrm{wt} \%$. 
A

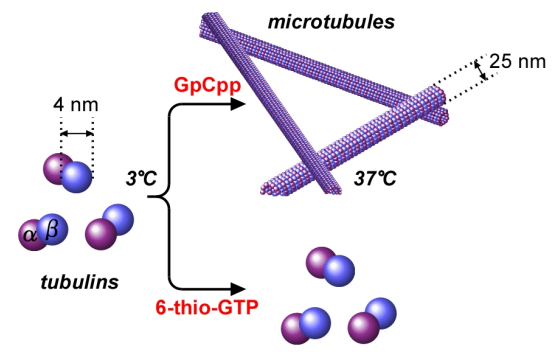

B
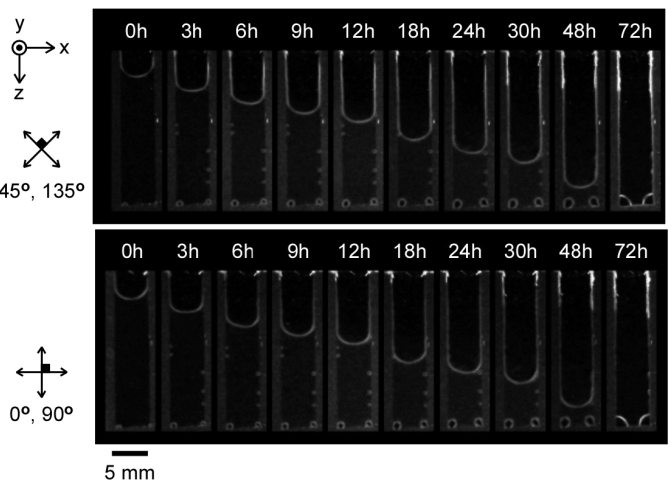

Figure S7. A. Control of tubulin/MT polymerization by GpCpp and 6-thio-GTP. B. Drying process of tubulin solution including 6-thio-GTP. Initial concentration of tubulin: $0.5 \mathrm{wt} \%$. Drying temperature: $37^{\circ} \mathrm{C}$.

Control of the tubulin/microtubules polymerization ${ }^{[6-8]}$ was carried out to clarify the effect of the polymerization on the orientation.

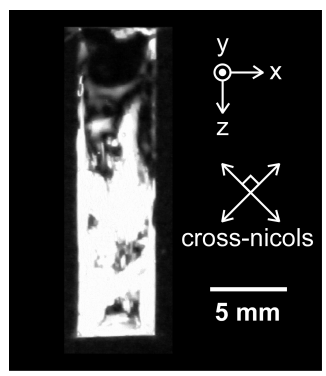

Figure S8. DNA solution in TE buffer at $\sim 25^{\circ} \mathrm{C}$. Initial concentration: $4 \mathrm{wt} \%$.

\section{References}

[1] M. K. Okajima, T. Bamba, Y. Kaneso, K. Hirata, E. Fukusaki, S. Kajiyama, T. Kaneko. Macromolecules 41, 4061(2008).

[2] M. K. Okajima, Q. T. Nguyen, S. Tateyama, H. Masuyama, T. Tanaka, T. Mitsumata, T. Kaneko. Biomacromolecules 13, 4158 (2012).

[3] A. C. S. Alcantara, M. Darder, P. Aranda, S. Tateyama, M. K. Okajima, T. Kaneko, M. Ogawa, E. Ruiz-Hitzky. J. Mater. Chem. A 2, 1391 (2014).

[4] M. K. Okajima, R. Mishima, K. Amornwachirabodee, T. Mitsumata, K. Okeyoshi, T. Kaneko. RSC Advances 5, 86723 (2015).

[5] K. Amornwachirabodee, M. K. Okajima, T. Kaneko. Macromolecules 48, 8615 (2015).

[6] K. Okeyoshi, R. Kawamura, R. Yoshida, Y. Osada. J. Mater. Chem. B 2, 41 (2014).

[7] K. Okeyoshi, R. Kawamura, R. Yoshida, Y. Osada. Chem. Commun. 51, 11607 (2015).

[8] K. Okeyoshi, R. Kawamura, R. Yoshida, Y. Osada. Sci. Rep. 5, 9581 (2015). 